\title{
Assessment of risks of loose landslide deposits formed by the 2008 Wenchuan earthquake
}

\author{
S. Zhang ${ }^{1}$, L. M. Zhang ${ }^{1}$, M. Peng ${ }^{1}$, L. L. Zhang ${ }^{2}$, H. F. Zhao ${ }^{1}$, and H. X. Chen ${ }^{1}$ \\ ${ }^{1}$ Department of Civil and Environmental Engineering, The Hong Kong University of Science and Technology, \\ Clear Water Bay, Hong Kong \\ ${ }^{2}$ Department of Civil Engineering, Shanghai Jiaotong University, Shanghai, China
}

Correspondence to: L. M. Zhang (cezhangl@ust.hk)

Received: 16 November 2011 - Revised: 16 January 2012 - Accepted: 15 February 2012 - Published: 9 May 2012

\begin{abstract}
A Geographic Information System (GIS)-based quantitative risk assessment methodology was adopted to evaluate the risks of loose deposits formed by the 2008 Wenchuan earthquake along a highway near the epicenter. A total of 305 loose deposits with a total volume of $4.0 \times 10^{7} \mathrm{~m}^{3}$ has been identified. A physical model was used to determine the failure probability of these loose deposits under six rainfall scenarios, assuming the loose deposits as infinite slopes. The calculated probability of rain-induced slope failures is verified by the recorded landslides at the same site during a storm in 2010. Seventy-nine out of the 112 rain-induced loose deposit failures are predicted by the reliability analysis, with an accuracy of $71 \%$. The results of reliability analysis and information on the consequence of these rain-induced landslides enable the estimation of the annual societal and individual risks of the loose deposits. Under the rainfall scenarios of $30 \mathrm{~mm} / 12 \mathrm{~h}$ and $70 \mathrm{~mm} / 12 \mathrm{~h}$, the estimated annual societal risks reach 8.8 and 7.5, respectively, and the individual risks reach 0.05 and 0.04, respectively, which are very high compared with present risk acceptance criteria. The preliminary assessment provides a benchmark for studying the long-term risks of these loose deposits and engineering decision.
\end{abstract}

\section{Introduction}

The 2008 Wenchuan earthquake in China triggered numerous landslides. The debris of these landslides deposited on steep terrains. Under normal weather conditions, such deposits are at a quasi-stable state. In the wet season, many of these deposits may lose stability due to rainfall infiltration.
The $45 \mathrm{~km}$ reach of Province Road 303 (PR303) is the only path from the epicenter, Yingxiu, to the Research and Conservation Centre for Giant Panda at Wolong (Fig. 1). The reconstruction of PR303 started in April 2009. Although efforts have been made to remove or strengthen some unsafe slopes, many deposits at high elevations have not been identified and some of them failed under rainfall conditions. During the rainy seasons of 2009-2011, numerous landslides were induced by rainfall, which caused a large number of casualty and serious damage to properties. It is expected that rainfall induced slope failures will continue to occur in the coming years. Therefore, it is important to evaluate the risks of these loose deposits so that the potential loss of life can be reduced in the future. The risk assessment in this paper was undertaken along PR303 from milestone K1 to K18 as shown in Fig. 1.

Risk can be defined as the potential adverse consequences, loss, harm or detriment (Royal Society, 1992). Landslide risk assessment has gained much attention in the past decades (e.g. Sassa et al., 2004; Nadim et al., 2006; Cascini, 2008; Fell et al., 2008; Salvati et al., 2010; Tang and Zhang, 2011). Sterlacchini et al. (2007) described a multi-disciplinary approach of landslide risk analysis. Einstein (1997) suggested that landslide risk assessment and management procedures start with assessing the state of nature and end with actions which include a variety of active or passive countermeasures to cope with landslides.

Numerous landslides can be triggered simultaneously by one rainstorm event and a particular element at risk may be exposed to multiple landslide hazards (Zhang, 2009). A quantitative risk analysis (QRA) requires the availability of sufficient historical landslide information in order to estimate the spatial, temporal and magnitude probabilities (Einstein, 


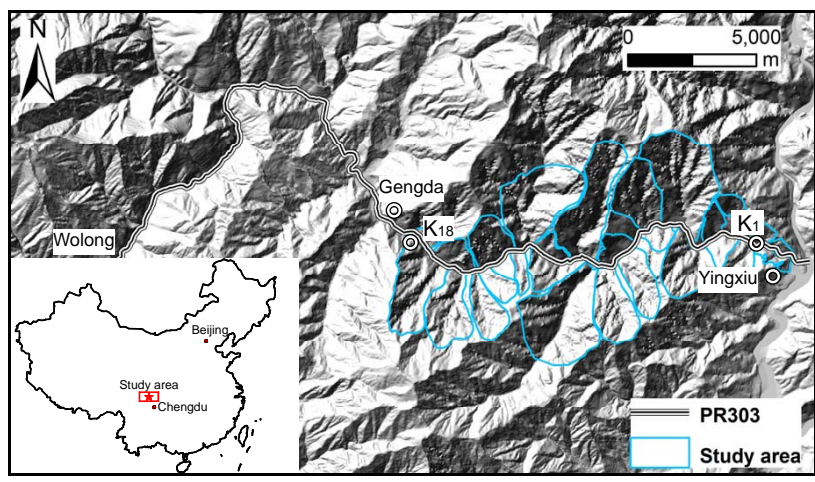

Fig. 1. Location of the study area and PR303.

1997). Although numerous landslides had been triggered by the Wenchuan earthquake, historical data on rainfall-induced landslides in loose deposits at a specific site are insufficient since this earthquake just happened $3 \mathrm{yr}$ ago. Hence, it is not feasible to carry out a QRA entirely based on statistical data.

This research aims to present a physically based method to estimate the risks of rainfall induced failures of loose deposits between K1 and K18 along PR303 shortly after the earthquake (Fig. 1). First, 305 loose deposits distributed in 27 catchments along this road were identified. Second, the reliability of these loose deposits under six rainfall scenarios was evaluated using rainfall infiltration analysis and slope stability analysis. The analysis was tested with observed failures of loose deposits during a storm in 2010. Finally, the potential loss of human lives due to failure of these deposits was assessed. The risks are expressed in terms of both societal risk and individual risk.

\section{Study site}

\subsection{Geological conditions}

The alignment of PR303 between $\mathrm{K} 1$ and $\mathrm{K} 18$ is primarily along the Yuzixi River that is bounded by terrains with elevations from 880 to $4140 \mathrm{~m}$. A GIS platform was used to study the topography, geology and river system in the study area based on a 20-m resolution digital elevation model (Fig. 2). The terrain in this area is rugged with steep slopes exceeding $40^{\circ}$ in many places, as a slope gradient analysis reveals in the GIS platform (Fig. 3). The slope gradient in the area was divided into 10 levels from $0^{\circ}$ to $90^{\circ}$. From $\mathrm{K} 1$ to $\mathrm{K} 18$, the slope gradients mainly range from $20^{\circ}$ to $50^{\circ}$ on both sides of PR303. The slope gradient on the west side of K18 near Gengda is mainly in the range of $0^{\circ}$ to $30^{\circ}$. The geological setting between K1 and K18 mainly consists of medium fine-grained granite and diorite (Fig. 4). These hard rocks explain why the topography of the study area can be so steep. Furthermore, the study area goes across four faults and is located at the hanging wall of a fault where strong motions

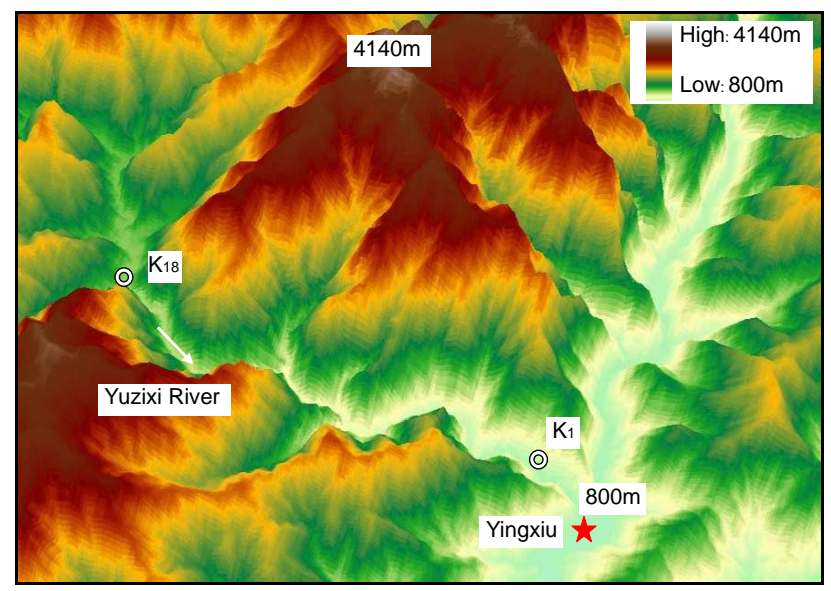

Fig. 2. Topography of PR303 between K1 and K18.

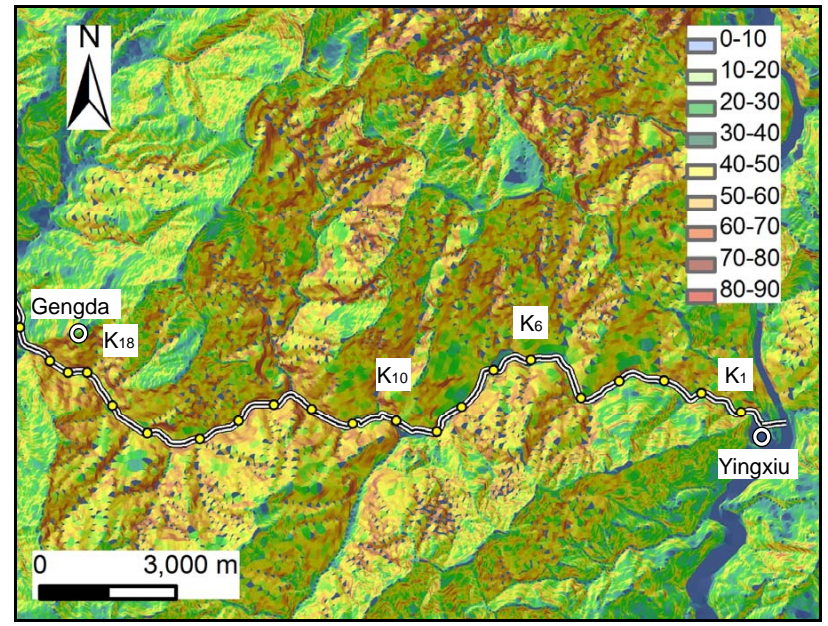

Fig. 3. Gradient of the natural terrain in the study area.

happened during the Wenchuan earthquake. The special geological structure contributed to the contrasting landsliding scenarios taking K18 (Gengda) as a boundary.

\subsection{Hydrological conditions}

Rainfall records of the Yingxiu area indicate that the average annual precipitation ranges from 1002 to $1265 \mathrm{~mm}$ and approximately $66-76 \%$ of rainfall occurs during the rainy season from June to August. In the study area, due to the discrepancy in topography, the temperature and rainfall vary greatly. The groundwater is mainly magmatic rock fissure water. It is shallowly restored, and the supply is almost equal to the discharge. After the Wenchuan earthquake, the study area suffered from several rainstorms. Of these events, the rainstorm on 14 August 2010 was the heaviest, with a total precipitation of $163 \mathrm{~mm}$ within $8 \mathrm{~h}$. The landslide events triggered by this storm event were used to verify the theoretical landslide probability for the loose deposits. 


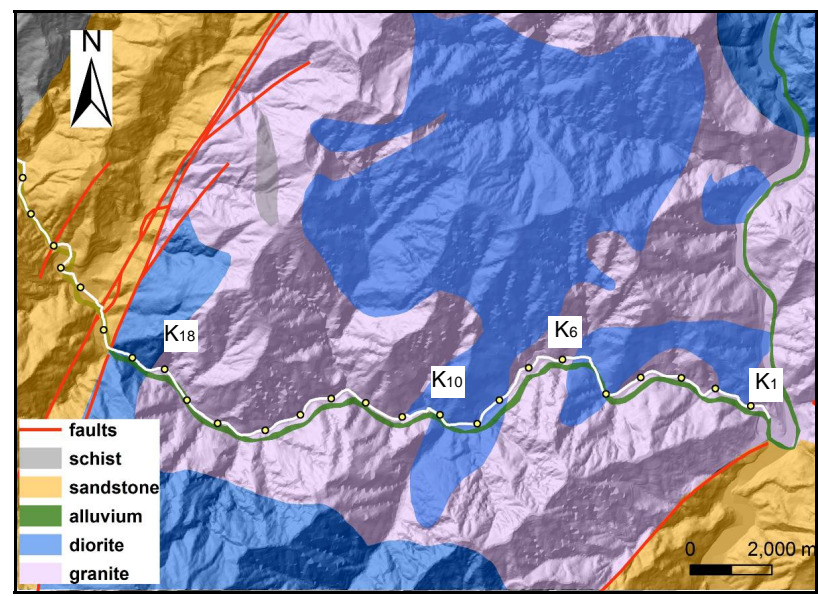

Fig. 4. Lithology and faults in the study area.

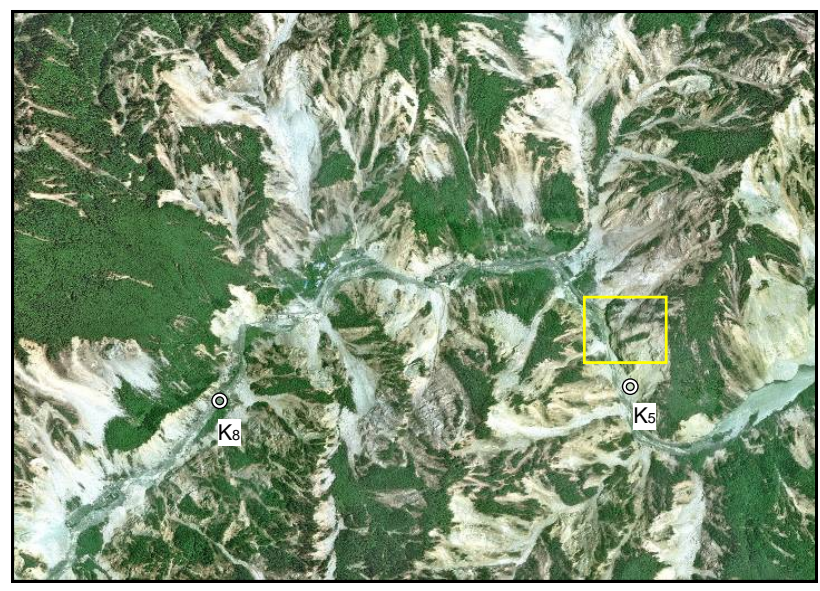

Fig. 5. Satellite image of loose deposits along PR303 shortly after the earthquake. Note: the detail of the marked part is shown in Fig. 6.

\section{Hazardous loose deposits}

The most common methods for geological hazard identification are based on satellite images, aerial-photo interpretation, field surveys and collection of local data. In this paper, interpretation of Quick-bird satellite images taken on 30 May 2008 combined with field investigations allowed the identification of a large number of loose deposits formed during the Wenchuan earthquake over a large area. The slope geometry was measured and the boundaries of catchments that affect a particular element at risk were delineated with the assistance of a GIS platform. These made it possible to estimate the likelihood of failure of the deposits and find likely deposition areas of the landslide debris where landslides could be reactivated.

As shown in Figs. 5 and 6, the road was largely buried or destroyed by densely populated loose deposits formed by

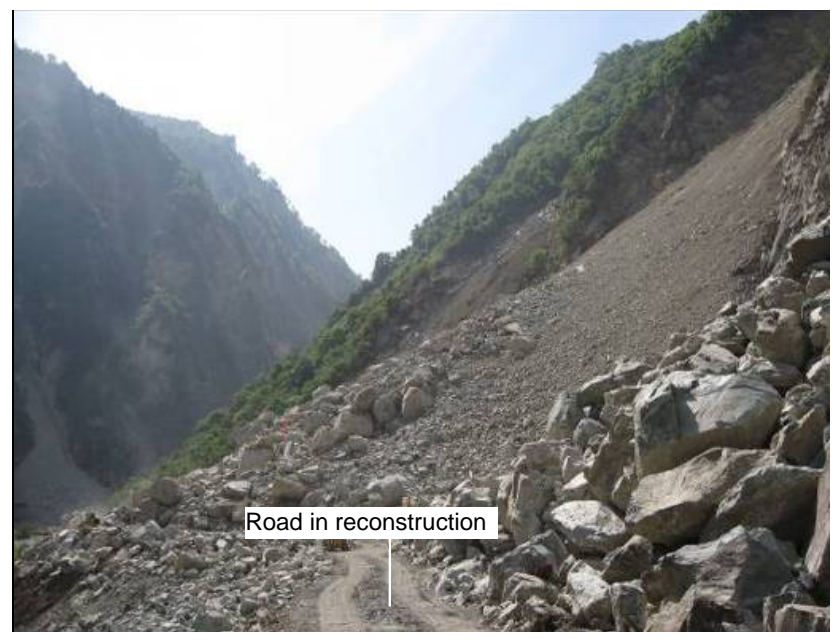

Fig. 6. Photo of a loose deposit that buried a part of PR303.

collapses during the earthquake. Identifying the hazards is of great significance to the re-reconstruction of the road. In order to quantify the impact of such loose deposits, a landslide inventory was generated for the study area (Fig. 7) based on available photos, satellite images and field investigations. As Fig. 7 reveals, a total of 305 loose deposits were identified, which were distributed along PR303 from K1 to K18 in 27 catchments of various watershed areas. The slope gradients of the 305 loose deposits ranged from $6^{\circ}$ to $48^{\circ}$. The steepest loose deposit was No. 109 with an average gradient of $48^{\circ}$ distributed in Yingchanggou Ravine. By measuring the scar and deposition areas of 25 selected slides during the field investigations, the average ratio of scar area and deposition area was determined as 1:3. The deposit depths in the scar area and the deposition area were on average $1 \mathrm{~m}$ and $3 \mathrm{~m}$, respectively. Therefore, based on the covering area, the volume of each loose deposit and the total volume of debris materials in each catchment were evaluated. The total volume of the 305 loose deposits was approximately $4.0 \times 10^{7} \mathrm{~m}^{3}$. The largest one was deposit No. 113 in Yinchanggou Ravine with a slope gradient of $21^{\circ}$ and a covering area of $464006 \mathrm{~m}^{2}$, located at elevations between $2300 \mathrm{~m}$ and $3190 \mathrm{~m}$.

\section{Risk assessment methodology}

In this paper, risks are presented in two formats. One is societal risk, which concerns the risk to the population as a whole, independent of geographical location. Traditionally, the societal risk is expressed in terms of an F-N curve, i.e. a graphical representation of the cumulative frequency of $\mathrm{N}$ or more fatalities (viz. F) against the number of fatalities (viz. N) on a log-log scale. The annual potential loss of life can be used to express the societal risk. The other format is individual risk, which regards the risk to a single person at a specific location (e.g. Wong et al., 1997). 


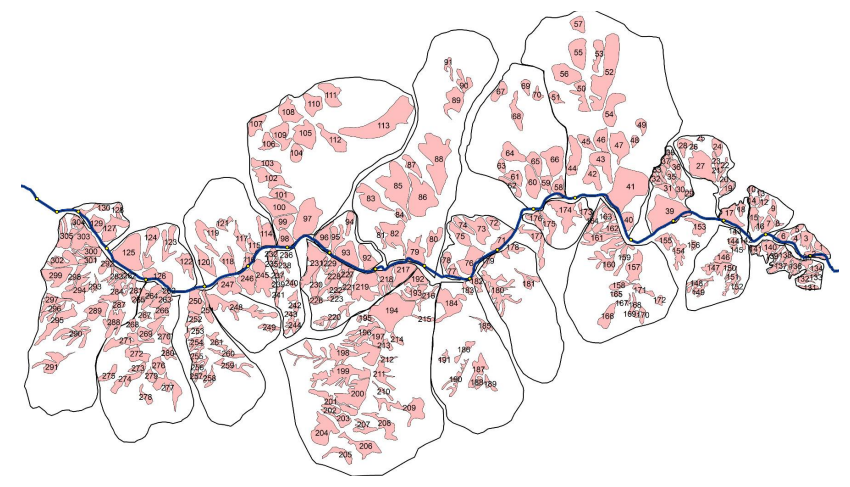

Fig. 7. Distribution of 305 loose deposits between K1 and K18 along PR303.

Suppose there were $n$ mutually exclusive landslide events. The societal risk was defined as the sum of the products of the conditional temporary and spatial probabilities and the consequence caused by the individual loose deposits. The annual potential loss of life, $R_{(\mathrm{LOL})}$, is quantified by (Morgan et al., 1992):

$R_{(\mathrm{LOL})}=\sum_{i=1}^{n}\left[P_{(L) i} \times P_{(T: L) i} \times P_{(S: T) i}\right] \times\left[V_{(D: S) i} \times E_{i}\right]$

where $P_{(L) i}, P_{(T: L) i}$ and $P_{(S: T) i}$ are the annual probability of landslide incident $i$, the probability of the landslide reaching the highway and the probability that passengers are present at the location impacted by landslide incident $i$, respectively; $V_{(D: S) i}$ is the vulnerability of the passengers to landslide event $i$ (i.e. the chance of the passengers lose their lives when they are impacted by the landslide); $E_{i}$ is the number of persons at risk by landslide incident $i$.

The individual risk of loss of life, $R_{(D I)}$, can be calculated from (Australian Geomechanics Society Sub-Committee on Landslide Risk Management, 2000):

$R_{(D I)}=\sum_{i=1}^{n} P_{(L) i} \times P_{(T: L) i} \times P_{(S: T) i} \times V_{(D: S)} i$

where $R_{(D I)}$ is the risk based on the annual probability of loss of life of an individual.

According to Eqs. (1) and (2), the first step to assess the risks of the loose soil deposits is hazard identification. The second step is to perform reliability analysis to determine the failure probability of the loose deposits. The third step is to evaluate the vulnerability by calculating the debris run-out distances. Meanwhile, the element at risk must be computed in line with design traffic conditions. Then the risks can be estimated.

\section{Determination of occurrence probability}

Physical-based slope stability analysis and Monte Carlo simulation were adopted in this paper to calculate the failure

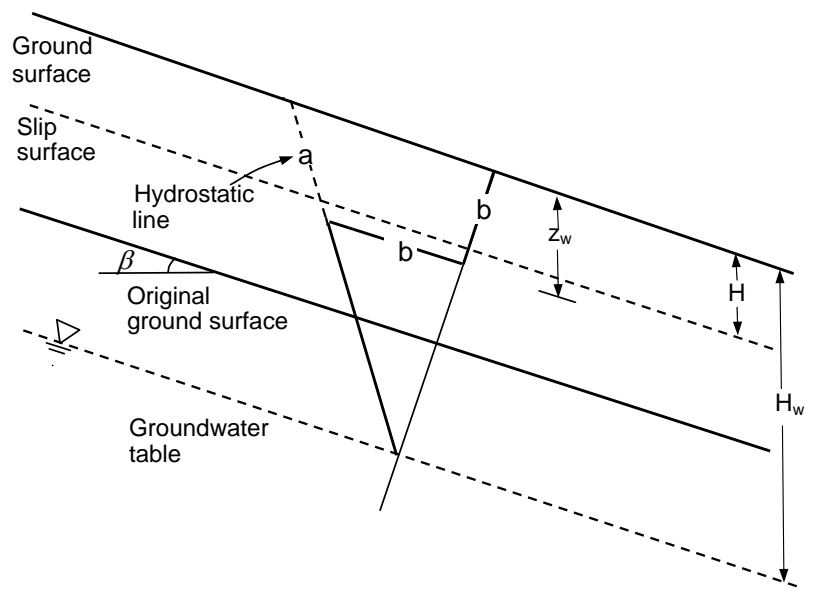

Fig. 8. Stability of an infinite loose soil deposit.

probability of each deposit under different rainfall levels. In order to test the calculation results, rainfall-induced failures of the loose deposits during the 14 August 2010 storm were interpreted by comparing the satellite images taken shortly after the 2008 earthquake and shortly after the $14 \mathrm{Au}$ gust 2010 rainstorm.

\subsection{Reliability of the deposits during rainfall infiltration}

Methods for the analysis of rainfall-induced slope failures have been recently reviewed by Zhang et al. (2005), L. L. Zhang et al. (2011). The geological conditions and rainfall characteristics vary significantly along the road and data of the rainfall-induced landslides in the past $3 \mathrm{yr}$ are limited. Hence, it is difficult to establish credible rainfall-landslide correlations for general uses. Thus, physically based models were used to assess the landslide risks instead. The site information needed for the models includes the slope gradient, soil properties, and thickness of each of the loose deposits. The slope gradient was calculated based on the GIS digital elevation model. The thicknesses of the deposits were typically small while their plan dimensions are large. The mean value of the individual loose deposit area was $50698 \mathrm{~m}^{2}$. The soil thickness was assumed to be $3 \mathrm{~m}$, which was far less than the plan dimensions. Therefore, these deposits can be assumed as infinite slopes for risk analysis purposes, as shown in Fig. 8. The initial ground water table was assumed to be $4.0 \mathrm{~m}$ below the original ground surface, or $7.0 \mathrm{~m}$ below the deposit surface.

Seepage analysis was conducted to investigate the infiltration of rainfall during six levels of rain (Table 1). The infiltration process was simulated using saturated/unsaturated finite element seepage analysis and a computer program SEEP/W (Geo-slope International Ltd., 2004) was used to compute the pore-water pressures in the loose deposits. Sieving tests were conducted at carefully selected sites and the 
Table 1. Classification of six rainfall scenarios.

\begin{tabular}{lllrl}
\hline Class & Intensity & $\begin{array}{l}\text { 12-h rainfall } \\
\text { rainfall }(\mathrm{mm})\end{array}$ & $\begin{array}{r}\text { Considered 12-h } \\
\text { rainfall }(\mathrm{mm})\end{array}$ & Annual probability ${ }^{2}$ \\
\hline 0 & No rain & 0 & - & - \\
1 & Light rain & $0.1-4.9$ & 5 & 1 \\
2 & Moderate rain & $5.0-14.9$ & 15 & 1 \\
3 & Heavy rain & $15.0-29.9$ & 30 & 0.7826 \\
4 & Torrential rain & $30.0-69.9$ & 70 & 0.2842 \\
5 & Large storm & $70.0-139.9$ & 140 & 0.0517 \\
6 & Extreme storm & $\geq 140$ & 240 & 0.006175 \\
\hline
\end{tabular}

${ }^{1}$ Based on China National Standardization Commission (2008); ${ }^{2}$ based on Sichuan Provincial Central Hydrological Station (1979).

main debris materials are classified as silty gravel or silty sand (e.g. Chang et al., 2011). The soil-water characteristic curves and permeability functions for similar coarse soils have been measured earlier ( $\mathrm{Li}$ et al., 2009a, b). The soilwater characteristic curves and permeability functions for the two soil layers in Fig. 8 are assumed with reference to results of Li et al. (2009a, b) and are shown in Fig. 9. The saturated coefficients of permeability $k_{\text {sat }}$ for the two layers are equal to $4.55 \times 10^{-5} \mathrm{~m} \mathrm{~s}^{-1}$ and $4.55 \times 10^{-6} \mathrm{~m} \mathrm{~s}^{-1}$, respectively. These curves are fitted using the models proposed by Fredlund and Xing (1994). Measurement of the hydraulic functions for specific soil deposits is needed in the future. The initial condition was established assuming a steady state condition subject to a constant rate of rainfall equivalent to the average annual rainfall evenly spread over the year $\left(3.58 \times 10^{-8} \mathrm{~m} \mathrm{~s}^{-1}\right)$. The sliding depth was affected by the ground water table. When the infiltration front reaches the original ground water table, the water table will rise. Figure 10 shows the pore water pressure distributions in a $40^{\circ}$ infinite slope subject to a sustained rain of $20 \mathrm{~mm} \mathrm{~h}^{-1}$ in intensity. The initial pore-water pressure is approximately linearly distributed. During the rainfall infiltration process, the wetting front advances gradually but the pore-water pressures in the wetted zone are still negative. The groundwater table rises gradually and is close to the original ground surface after $8 \mathrm{~h}$ of rain.

Rahardjo et al. (1995) derived equations for calculating the factor of safety, $F_{\mathrm{s}}$, of an infinite slope under different pore-water pressure conditions in Fig. 8. For the hydrostatic condition (profile $a$ ), $F_{\mathrm{S}}$ was expressed as:

$F_{\mathrm{s}}=\frac{c^{\prime}}{\gamma_{t} H \sin \beta \cos \beta}+\frac{\tan \phi^{\prime}}{\tan \beta}$

where $\beta=$ slope angle; $H=$ depth of sliding; $H_{\mathrm{w}}=$ depth of groundwater table; $c^{\prime}$ and $\phi^{\prime}=$ effective cohesion and friction angle of the soil, respectively; $\phi^{b}=$ friction angle related to the contribution of soil suction to the shear strength; $\gamma_{\mathrm{w}}$ and $\gamma_{\text {sat }}=$ unit weight of water and total unit weight of soil, respectively.

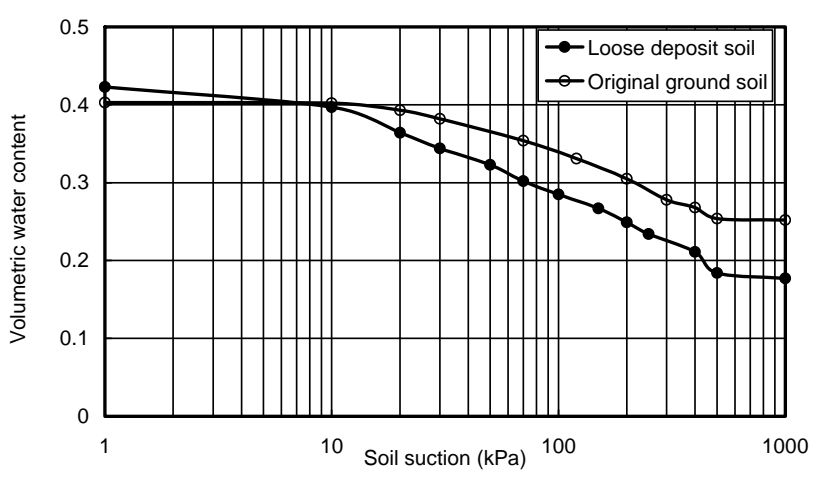

(a)

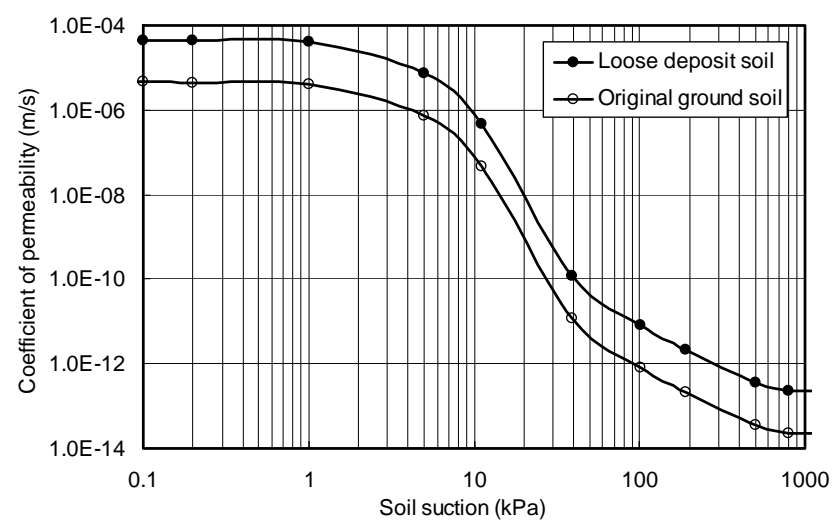

(b)

Fig. 9. Soil-water characteristic curves and permeability functions for seepage analysis.

The suction in the shallow soil dissipates as rainwater infiltrates. When the wetting front is at a depth $z_{\mathrm{w}}$ from the original ground surface (Fig. 8) and when the suction within the wetted zone is ignored, the factor of safety along the sliding surface at the wetting front is (profile $b$ )

$$
F_{\mathrm{s}}=\frac{c^{\prime}}{\gamma_{t} H \sin \beta \cos \beta}+\frac{\tan \phi^{\prime}}{\tan \beta} .
$$




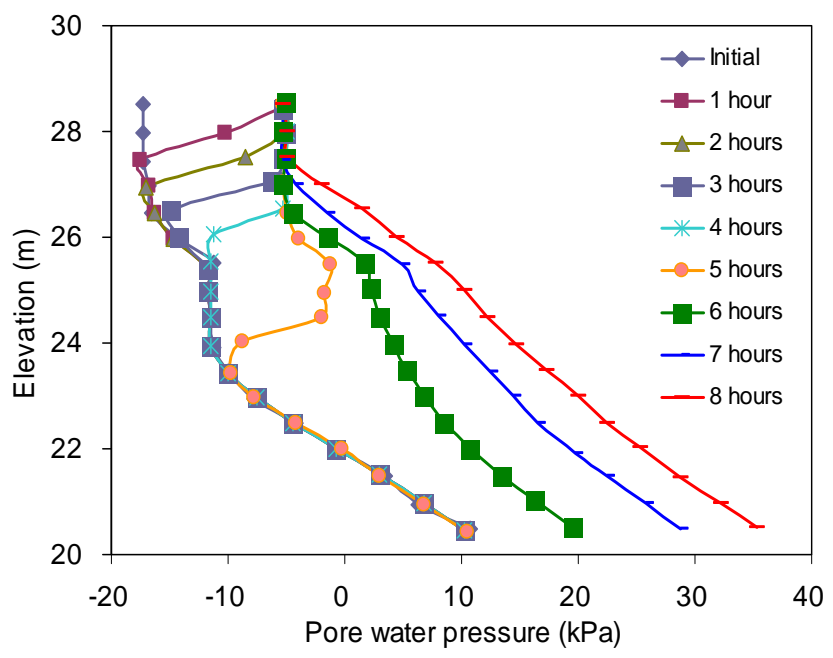

Fig. 10. Change of pore-water pressure with time during rainfall infiltration in a $40^{\circ}$ infinite slope.

Equation (4) shows that $F_{\mathrm{S}}$ decreases with the depth of sliding, $H$. Hence $H$ is taken as the infiltration depth.

When the wetting front reaches the interface between the loose deposit and the original ground surface, the water pressure will turn into positive and the factor of safety will decrease substantially as the groundwater table rises:

$F_{\mathrm{s}}=\frac{c^{\prime}}{\gamma_{t} H \sin \beta \cos \beta}+\frac{\tan \phi^{\prime}}{\tan \beta}-\frac{m \gamma_{\mathrm{w}} \tan \phi^{\prime}}{\gamma_{\mathrm{sat}} \tan \beta}$

where $m=\left(1-H_{\mathrm{w}} / H\right)>0$.

The failure probability of each deposit was calculated according to Eqs. (3)-(5) using Monte Carlo simulation, assuming that the sliding depth is equal to the wetting front depth. Cohesion $c^{\prime}$ and friction angle $\phi^{\prime}$ for the loose soil were assumed as two independent normally distributed random variables. The mean values of $c^{\prime}$ and $\phi^{\prime}$ were $8 \mathrm{kPa}$ and $32.7^{\circ}$, respectively, and their coefficients of variation were 0.32 and 0.14 , respectively following Tang and Zhang (2011). In each analysis, 65550 pairs of random variables for $c^{\prime}$ and $\phi^{\prime}$ were generated. The error of calculated probability of failure would be $7.8 \%$ if the mean probability of failure is 0.01 (Ang and Tang, 2007).

The stability of the loose deposits is categorized in Fig. 11 in terms of calculated probability of failure according to the qualitative measures of likelihood proposed by Australian Geomechanics Society Sub-Committee on Landslide Risk Management (2000). The qualitative measures provide a link between qualitative terms and indicative probabilities (Table 2). The failure of a slope was considered "Almost certain" if the probability of failure $P_{\mathrm{f}}>\approx 10^{-1}$, "Likely" if $P_{\mathrm{f}} \approx 10^{-2}$, "Possible" if $P_{\mathrm{f}} \approx 10^{-3}$, and "Unlikely" if $P_{\mathrm{f}} \approx 10^{-4}$. The regions of "Possible" and "Almost certain" to fail expanded greatly under the $140 \mathrm{~mm} / 12 \mathrm{~h}$ rainfall condition, as shown in Fig. 11e. Under the extreme rainstorm of $240 \mathrm{~mm} / 12 \mathrm{~h}$, the majority of the "Possible" to fail region becomes "Almost certain" to fail in Fig. 11f.

It should be noted that the loose deposits often fail locally. As time goes on, the geometry of the deposits may become more irregular and the infinite slope assumption will become less valid.

\subsection{Verification of calculated failure probability}

To test the reliability analysis results based on the physical models presented in Sect. 4.1, a comparison was made between two categories of images: Category 1 - Quickbird satellite images taken on 30 May 2008 shortly after the Wenchuan earthquake and Category 2 - Worldview-2 satellite images taken in 2010 shortly after the 14 August 2010 rainstorm event.

For the loose soil deposits identified from the Category-1 images shown in Fig. 7, the computed average failure probability of the 305 loose deposits using the physical models is $25.4 \%$ under the $240 \mathrm{~mm} / 12 \mathrm{~h}$ rainfall condition, which occurred during the 14 August 2010 rainstorm event. Among the 305 deposits, 125 deposits belong to the "Almost certain" category with failure probabilities above $10^{-1} ; 91$ deposits fall into the "Likely" category with failure probabilities between $10^{-1}$ and $10^{-2} ; 26$ deposits in the "Possible" category and 30 deposits in the "Unlikely" category.

The Category-2 images represent the real cases of rainfallinduced failures of the loose deposits during the $14 \mathrm{Au}$ gust 2010 rainstorm with a rainfall intensity of $240 \mathrm{~mm} / 12 \mathrm{~h}$. The reactivated loose deposits in this study were identified according to the newly exposed scars of landslides in the satellite images. A total of 112 loose failures in the Category2 images have been identified by fresh signs of exposed surfaces. Those failures were triggered by the 14 August 2010 storm. Shallow failures occurred in $33 \%$ of the 305 loose deposits. A total of 79 of the 112 rainfall-induced failures were indeed evaluated as "Almost certain" to occur in the reliability analysis, with an accuracy of $71 \%$.

\section{Assessment of consequence of landslides}

\subsection{Estimation of run-out distance}

Nicoletti and Sorriso-Valvo (1991) defined the run-out distance of a landslide as the distance from the topmost point of the head scarp to the farthest end of the landslide deposit. The run-out distance of the landslide can be used to determine the probability of a landslide reaching the elements at risk and the vulnerability factor. In Fig. $12, L$ is the run-out distance, $L_{0}$ is the projected distance from the landslide scar to the inside edge of the road, and $\Delta L$ is the travel difference between $L$ and $L_{0}$, which denotes the distance that the landslide debris runs out beyond the inside edge of the road. A positive value of $\Delta L$ indicates that the landslide debris buries 

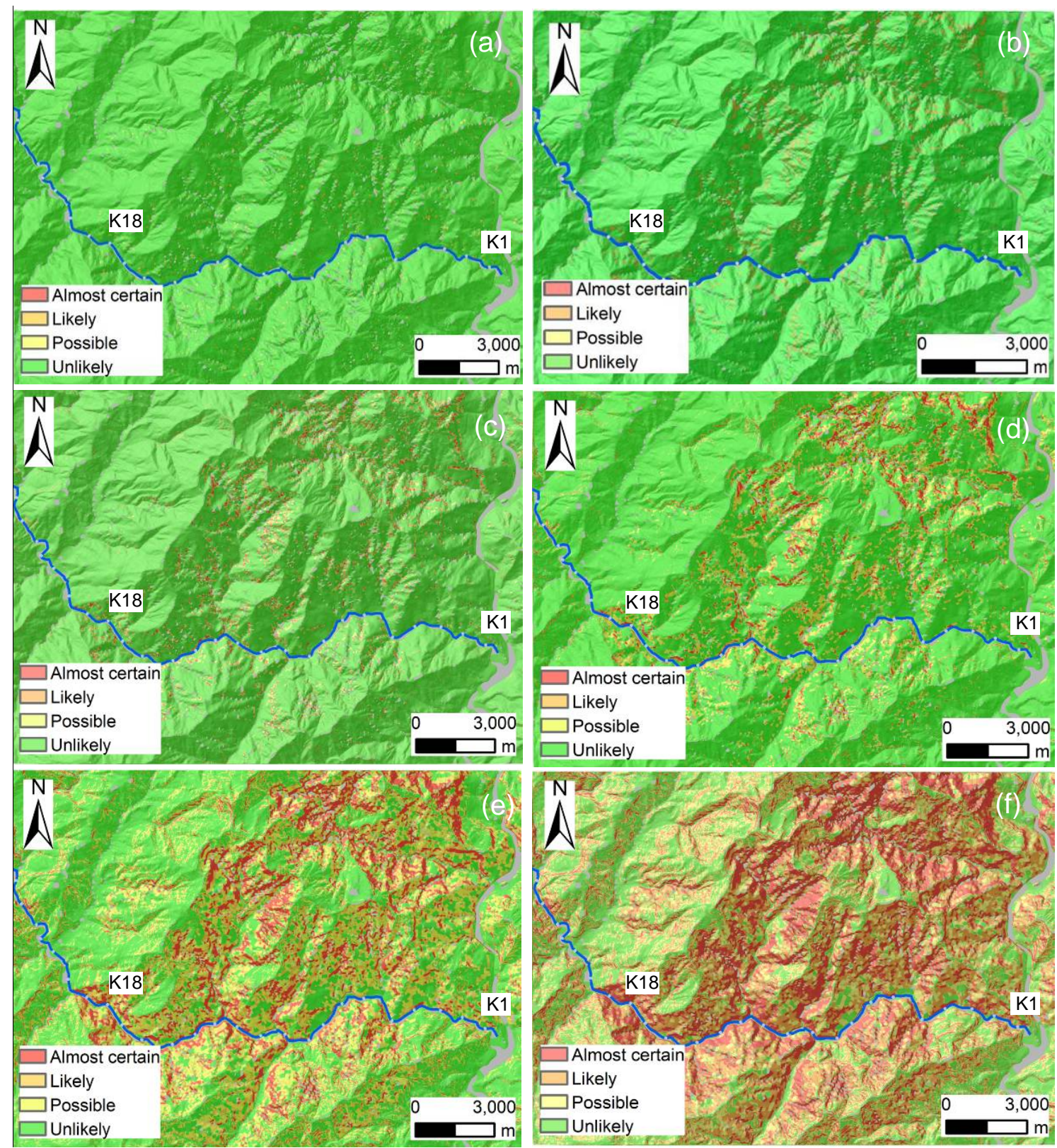

Fig. 11. Categories of possibility of failure of the loose deposits under six 12 -h rainfall scenarios (a: under $5 \mathrm{~mm} / 12 \mathrm{~h}$ rainfall; $\mathbf{b}$ : under $15 \mathrm{~mm} / 12 \mathrm{~h}$ rainfall; $\mathbf{c}$ : under $30 \mathrm{~mm} / 12 \mathrm{~h}$ rainfall; $\mathbf{d}$ : under $70 \mathrm{~mm} / 12 \mathrm{~h}$ rainfall; e: under $140 \mathrm{~mm} / 12 \mathrm{~h}$ rainfall; f: under $240 \mathrm{~mm} / 12 \mathrm{~h}$ rainfall).

Table 2. Qualitative measures of likelihood (modified from Australian Geomechanics Society Sub-Committee on Landslide Risk Management, 2000).

\begin{tabular}{lll}
\hline Descriptor & Description & $\begin{array}{l}\text { Indicative probability } \\
\text { of failure }\end{array}$ \\
\hline Almost certain & The slide is expected to occur & $>\approx 10^{-1}$ \\
Likely & The slide will probably occur under adverse conditions & $\approx 10^{-2}$ \\
Possible & The slide could probably occur under adverse conditions & $\approx 10^{-3}$ \\
Unlikely & The slide might occur under very adverse circumstances & $\approx 10^{-4}$ \\
\hline
\end{tabular}




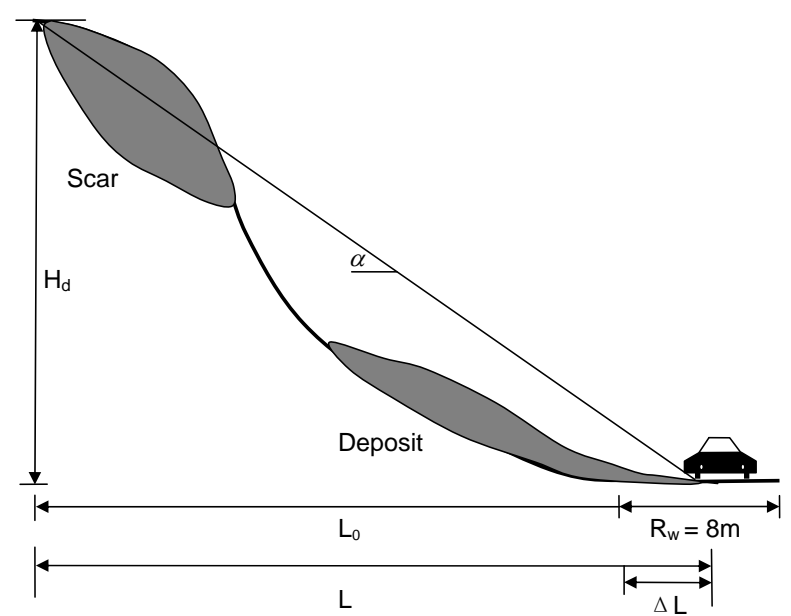

Fig. 12. Run-out distance of landslide debris.

the road, whereas a negative $\Delta L$ value reveals that the landslide debris does not reach the road and hence will not affect facilities located along the road at time of the landslide.

Many empirical relationships are widely used to estimate the run-out distance of landslide materials (e.g. Corominas, 1996; Legros, 2002; Finlay et al., 1999; Hunter and Fell, 2003). The relationship between landslide volume and reach angle, $\alpha$ (Fig. 12) proposed by Hunter and Fell (2003) was adopted here, which was established for flow slides in loose fill slopes:

$$
\frac{H_{\mathrm{d}}}{L}=0.67 \mathrm{~V}^{-0.882}
$$

where $H_{\mathrm{d}}$ is the elevation difference in Fig. 12; $V$ is the landslide volume, which can be calculated by multiplying the depth of sliding surface by the slide area. In this study, it is assumed that the sliding depth is equal to the depth of wetting front for an infinite slope and the slide area interpreted from satellite images is constant. The rationale to choose Eq. (6) is verified by information of six landslides during the Wenchuan earthquake (Fig. 13). A detailed study of particle flows observed in a large landslide event is presented by L. M. Zhang et al. (2011). Equation (6) slightly overestimates the value of $H_{\mathrm{d}} / L$ for the type of failures in the Wenchuan earthquake zone.

\subsection{Element at risk and vulnerability factor}

The element at risk is taken as the passengers travelling on the road who may be buried by the landslide debris. The size of the element at risk relates to the type of vehicles and the relevant landslides. The scaling is decided by the buried length of the road. In this paper, road passengers were regarded as the only element at risk. Assuming a constant traffic flow over the road segment concerned, the expected number of passengers at risk, $E$, in a landslide event is given by:

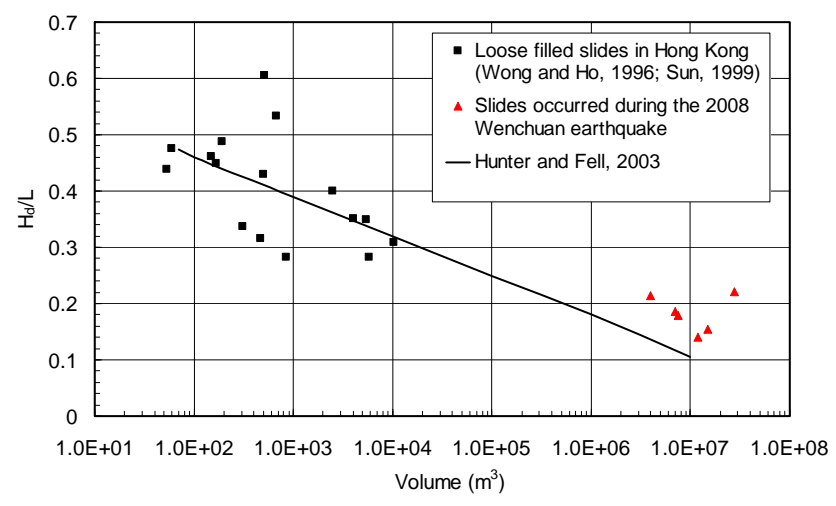

Fig. 13. An empirical model for predicting run-out distances of loose deposits.

$E=\frac{W T n}{v}$

where $T=$ number of vehicles passing through the road per second; $W=$ the length of road that is buried by the collapsed deposit, which can be determined by the width of the loose deposit; $v=$ design vehicle speed, $40 \mathrm{~km} \mathrm{~h}^{-1} ; n=$ average number of passengers in one vehicle. By counting both the number of vehicles passing by and the number of passengers in each vehicle within one hour, $n$ is determined as 2.35. The expected number of passengers at risk, $E$, is hence equivalent to 35 persons $\mathrm{km}^{-1}$.

The vulnerability factor can be defined as the probability of loss of life. It reflects the level of potential damage, or degree of loss, of a given element subjected to a landslide of a given intensity (Fell, 1994). Finlay et al. (1999) proposed vulnerability factors for several cases. If a vehicle is buried, the persons in the vehicle will be certain to die; the corresponding vulnerability factor value is then 1.0. According to the landslide run-out distance analysis results, the vulnerability given that a landslide buries the road (i.e. $\Delta L>0$ ), $V_{(D: T)}$, is taken as 1.0, considering that vehicles will be completely buried; namely, the passengers will be buried once a landslide runs over them (Australian Geomechanics Society Sub-Committee on Landslide Risk Management, 2000). Otherwise $V_{(D: T)}$ is taken as 0 .

\section{Results of quantitative risk analysis}

Given the values of conditional probability of failure, the element at risk and the vulnerability factor for each loose deposit, the societal and individual risks in six exclusive rainfall scenarios can be evaluated based on the respective assessment models, i.e. Eqs. (1) and (2).

The results of the societal risk $\left(R_{(\mathrm{LOL})}\right)$ of the loose deposits under six rainfall scenarios are listed in Table 3. A total of 305 loose deposits have been assessed. Based on the runout distances, not all the sliding deposits can reach the road. 


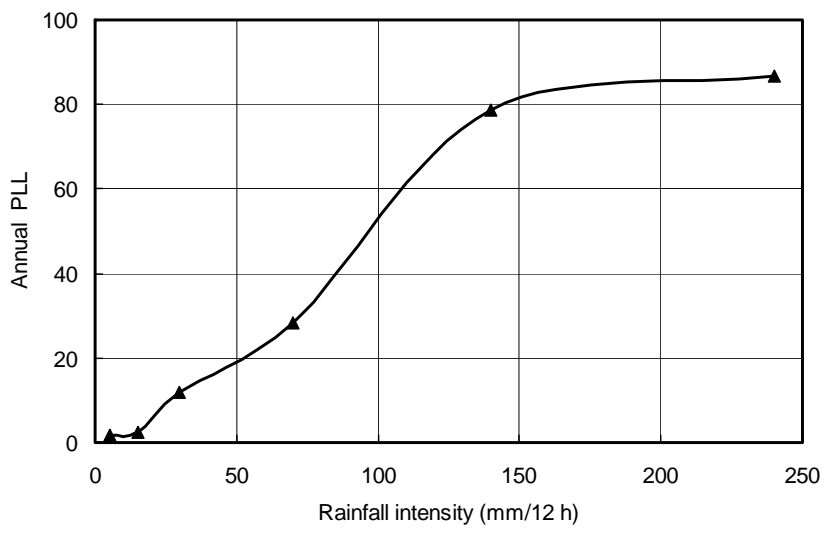

(a)

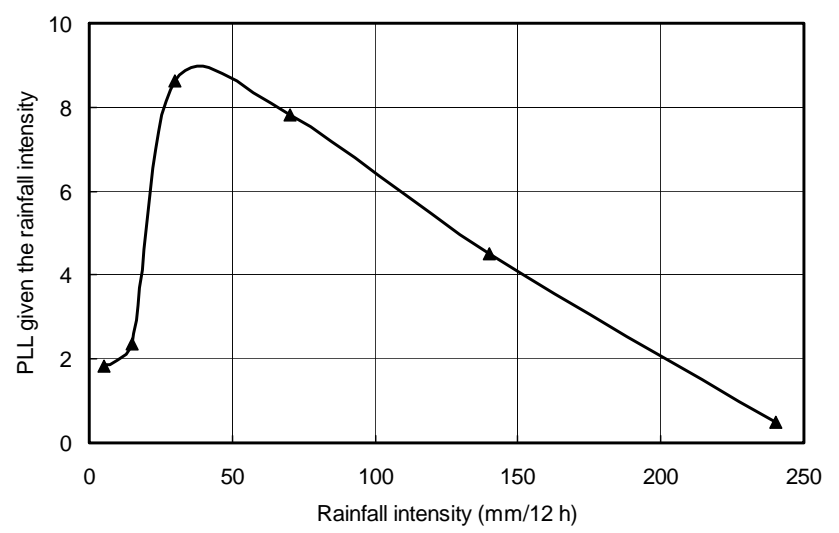

(b)

Fig. 14. Relationship between 12-h rainfall and PLL between K1 and K18 (a: Annual PLL; b: PLL given the rainfall intensity).

Hence, not all the deposits can bury the road and the passengers. The loose deposits with zero predicted societal risk are excluded in Table 3. The most serious cumulative risk from $\mathrm{K} 1$ to $\mathrm{K} 18$ is 8.82 under the $30 \mathrm{~mm} / 12 \mathrm{~h}$ rainfall condition followed by 7.48 under the $70 \mathrm{~mm} / 12 \mathrm{~h}$ rainfall condition. These imply that the most serious case happens when the rain level is $30 \mathrm{~mm} / 12 \mathrm{~h}$ (heavy rain) and $70 \mathrm{~mm} / 12 \mathrm{~h}$ (torrential rain) rather than an extreme storm $(240 \mathrm{~mm} / 12 \mathrm{~h})$, as shown in Table 1. The very low rainfall frequency of the extreme case $(240 \mathrm{~mm} / 12 \mathrm{~h})$, as one of the components of conditional probability, explains such a phenomenon well. The societal risk can also be graphically presented in the form of potential loss of life (PLL) (Fig. 14). The annual PLL and PLL given the rainfall intensity are both used to express the societal risk. Figure 14a shows that the annual PLL caused by the 305 loose deposits between K1 and K18 is closely related to the rainfall frequency. Figure $14 \mathrm{~b}$ shows the PLL values at given rainfall intensity values. The increment of risk is not significant when the rainfall intensity increases from $5 \mathrm{~mm} / 12 \mathrm{~h}$ to $15 \mathrm{~mm} / 12 \mathrm{~h}$ rain. However, the risk increases substantially when subject to a rain severer than $30 \mathrm{~mm} / 12 \mathrm{~h}$.

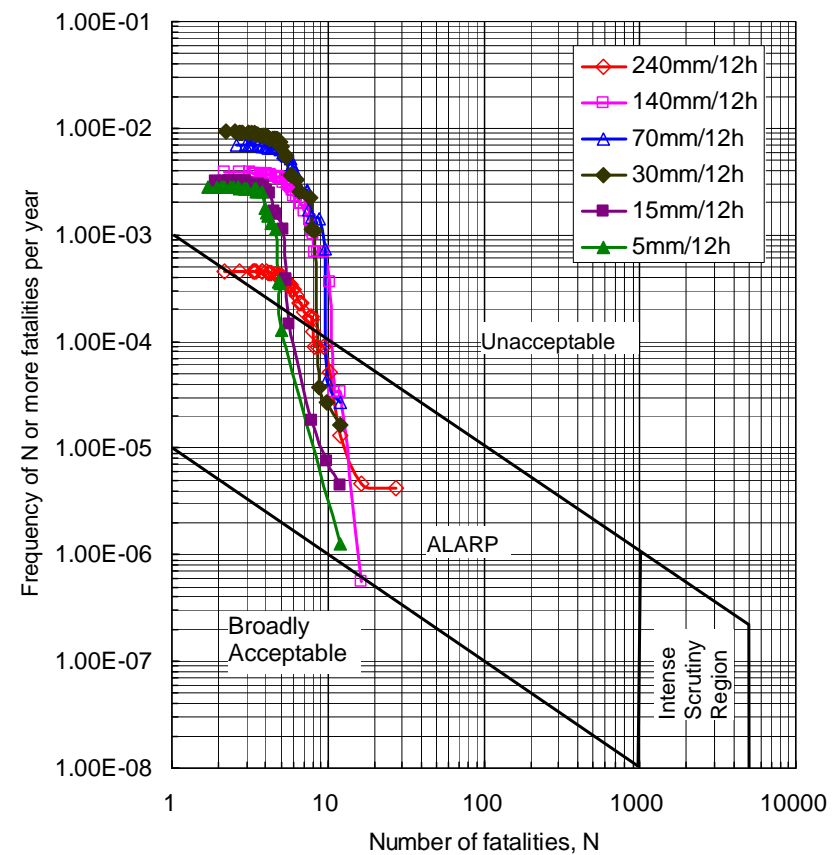

Fig. 15. F-N curves for K1-K18 shortly after the earthquake in six rainfall scenarios.

The societal risks of the loose deposits under the six rainfall conditions can also be presented in an F-N curve in Fig. 15. One of the advantages of an F-N curve is that it provides additional information on the full range of credible fatal scenarios and the corresponding likelihood of occurrence (Wong et al., 1997). The societal risk acceptance criteria proposed by GEO (1998) were adopted in this paper as a benchmark, which is suitable for a study area with a reference toe length of $500 \mathrm{~m}$ or smaller (Reeves et al., 1999). As shown in Fig. 15, the societal risk criteria involve a 3-tier system, which is the conventional approach incorporating an unacceptable region, a broadly acceptable region and an "As Low As Reasonably Practicable (ALARP)" region. The societal risks of the six rainfall scenarios are mainly located in the ALARP and unacceptable region. Under the extreme rainfall condition of $240 \mathrm{~mm} / 12 \mathrm{~h}$, the failure probability is high and the consequence is very serious, but the annual frequency is small. Hence, the final risk reflected in the F-N curve is not the worst. However, the risks of the $30 \mathrm{~mm} / 12 \mathrm{~h}$ (torrential rain) and $70 \mathrm{~mm} / 12 \mathrm{~h}$ (heavy rain) rainfall-intensity cases deserve more attention. Although the conditional probability and consequence are not the largest, the annual frequency is very high compared with the rainfall conditions of 240 and $140 \mathrm{~mm} / 12 \mathrm{~h}$.

The individual risks of the loose deposits are presented in Fig. 16. GEO (1998) set a maximum allowable individual risk at $10^{-5}$ for new developments and $10^{-4}$ for existing developments. All the individual risk results under different rainfall intensity values in this study are very high. 
Table 3. Results of annual societal risk $\left(R_{(\mathrm{LOL})}\right)$ for fatal loose deposit failures under six rainfall scenarios.

\begin{tabular}{|c|c|c|c|c|c|c|}
\hline Deposit ID & $240 \mathrm{~mm} / 12 \mathrm{~h}$ & $140 \mathrm{~mm} / 12 \mathrm{~h}$ & $70 \mathrm{~mm} / 12 \mathrm{~h}$ & $30 \mathrm{~mm} / 12 \mathrm{~h}$ & $15 \mathrm{~mm} / 12 \mathrm{~h}$ & $5 \mathrm{~mm} / 12 \mathrm{~h}$ \\
\hline 1 & 0.0009 & 0.0074 & 0.0059 & 0.0044 & 0.0017 & 0.0006 \\
\hline 2 & 0.0042 & 0.0353 & 0.0457 & 0.0302 & 0.0176 & 0.003 \\
\hline 3 & 0.0041 & 0.0346 & 0.0436 & 0.0293 & 0.0154 & 0.0032 \\
\hline 4 & 0.002 & 0.017 & 0.0196 & 0.0128 & 0.0074 & 0.0012 \\
\hline 5 & $8 \times 10^{-5}$ & 0.0007 & 0.0005 & 0.0003 & 0.0003 & 0.0003 \\
\hline 6 & 0.0008 & 0.0071 & 0.0056 & 0.0042 & 0.0016 & 0.0006 \\
\hline 7 & $5 \times 10^{-5}$ & 0.0004 & 0.0003 & 0.0003 & 0.0004 & 0.0003 \\
\hline 8 & $2 \times 10^{-6}$ & $2 \times 10^{-5}$ & $9 \times 10^{-5}$ & 0.0002 & 0.0002 & 0.0002 \\
\hline 9 & 0.0013 & 0.0105 & 0.0107 & 0.0073 & 0.0037 & 0.0006 \\
\hline 10 & $2 \times 10^{-6}$ & $2 \times 10^{-5}$ & $9 \times 10^{-5}$ & 0.0002 & 0.0002 & 0.0002 \\
\hline 11 & 0.0003 & 0.0025 & 0.0024 & 0.0012 & 0.0008 & 0.0002 \\
\hline 12 & 0.0022 & 0.018 & 0.0208 & 0.0135 & 0.0078 & 0.0013 \\
\hline 13 & $4 \times 10^{-6}$ & $3 \times 10^{-5}$ & $9 \times 10^{-5}$ & 0.0002 & 0.0002 & 0.0002 \\
\hline 14 & $2 \times 10^{-6}$ & $2 \times 10^{-5}$ & 0.0001 & 0.0002 & 0.0003 & 0.0002 \\
\hline 15 & 0.0069 & 0.0576 & 0.0793 & 0.0521 & 0.0296 & 0.0056 \\
\hline 16 & 0.0006 & 0.0051 & 0.0041 & 0.003 & 0.0012 & 0.0004 \\
\hline 17 & $6 \times 10^{-5}$ & 0.0005 & 0.0004 & 0.0004 & 0.0005 & 0.0004 \\
\hline 18 & 0.0081 & 0.0674 & 0.1011 & 0.0675 & 0.0389 & 0.008 \\
\hline 19 & 0.0098 & 0.0443 & 0.0422 & 0.0237 & 0.0043 & 0.0024 \\
\hline 29 & 0.0181 & 0.0341 & 0.0345 & 0.0188 & 0.0048 & 0.0006 \\
\hline 30 & 0.0126 & 0.0264 & 0.0245 & 0.0157 & 0.0042 & 0 \\
\hline 31 & 0.0051 & 0 & 0 & 0 & 0 & 0 \\
\hline 40 & $1.83 \times 10^{-5}$ & 0.0045 & 0.0025 & 0.0016 & 0.0006 & 0 \\
\hline 41 & 0.0079 & 0.0609 & 0.0501 & 0.0308 & 0.0083 & 0 \\
\hline 42 & 0.0008 & 0.0014 & 0 & 0 & 0 & 0 \\
\hline 43 & $5 \times 10^{-6}$ & 0 & 0 & 0 & 0 & 0 \\
\hline 44 & 0.0002 & 0.0003 & 0 & 0 & & \\
\hline 45 & 0.0451 & 0.0008 & 0 & 0 & 0 & 0 \\
\hline 46 & 0.002 & 0 & 0 & 0 & 0 & 0 \\
\hline 47 & 0.0004 & 0 & 0 & 0 & 0 & 0 \\
\hline 48 & 0.0001 & 0.3326 & 0.1241 & 0.77 & 0.0117 & 0.0062 \\
\hline 49 & $8 \times 10^{-6}$ & 0.0244 & 0.0142 & 0.184 & 0.0014 & 0.0004 \\
\hline 50 & $3 \times 10^{-6}$ & 0.0084 & 0.0041 & 0.17 & 0 & 0 \\
\hline 51 & $6 \times 10^{-7}$ & 0.0022 & 0.0004 & 0.1712 & 0 & 0 \\
\hline 52 & $9.03 \times 10^{-8}$ & 0.0011 & 0 & 0 & 0 & 0 \\
\hline 54 & $2.9 \times 10^{-7}$ & $6 \times 10^{-5}$ & 0 & 0 & 0 & 0 \\
\hline 56 & 0.007135 & 0.0096 & 0.1266 & 0 & 0 & 0 \\
\hline 57 & 0.004792 & 0.0136 & 0.0695 & 0.0443 & 0 & 0 \\
\hline 59 & 0.0152 & 0.0678 & 0.0652 & 0.0461 & 0.0126 & 0 \\
\hline 60 & 0.0006 & 0.0011 & 0.0003 & 0 & 0 & 0 \\
\hline 61 & 0.0022 & 0.008 & 0 & 0 & 0 & 0 \\
\hline 62 & 0.0274 & 0.1779 & 0.3404 & 0.1955 & 0.1084 & 0 \\
\hline 63 & 0.0056 & 0.0609 & 0.2119 & 0.002 & 0.0756 & 0 \\
\hline 64 & 0.0002 & 0.0015 & 0.0023 & 0 & 0 & 0 \\
\hline 105 & 0.0363 & 0.3141 & 0.5346 & 0.6865 & 0.5193 & 0.4654 \\
\hline 106 & 0.042 & 0.4162 & 0.2651 & 0.3225 & 0.1116 & 0.1 \\
\hline 108 & 0.0377 & 0.3226 & 0.6315 & 0.8423 & 0 & 0 \\
\hline 110 & 0.0412 & 0.3459 & 1.0165 & 1.4604 & 0.3012 & 0.1452 \\
\hline 112 & 0.0167 & 0.323 & 0.0198 & 0.0194 & 0 & 0 \\
\hline 113 & 0.0616 & 0.5272 & 1.032 & 1.3766 & 0 & 0 \\
\hline 115 & 0.025 & 0.2619 & 0.1292 & 0.1479 & 0.0031 & 0 \\
\hline 123 & 0.0571 & 0.4882 & 0.9557 & 1.2747 & 0 & 0 \\
\hline 140 & 0.0008 & 0.0025 & 0 & 0 & 0 & 0 \\
\hline 141 & 0.0132 & 0 & 0 & 0 & 0 & 0 \\
\hline 142 & 0.0023 & $3 \times 10^{-5}$ & 0.1251 & 0 & 0 & 0 \\
\hline 143 & 0.002 & 0.0322 & 0.0342 & 0 & 0 & 0 \\
\hline 144 & $5 \times 10^{-5}$ & 0.0176 & 0.0149 & 0.0443 & 0.0045 & 0 \\
\hline 179 & 0.0011 & 0 & 0 & 0 & 0 & 0 \\
\hline 185 & $6 \times 10^{-5}$ & 0.0023 & 0 & 0 & 0 & 0 \\
\hline 188 & 0.0102 & 0.0358 & 0 & 0 & 0 & 0 \\
\hline 193 & 0.0013 & 0.0153 & 0.1166 & 0.1935 & 0 & 0 \\
\hline 244 & 0.0357 & 0.0340 & 0.1095 & 0.002 & 0 & 0 \\
\hline 245 & 0.0002 & 0.0202 & 0.0062 & 0 & 0 & 0 \\
\hline 249 & 0.0034 & 0 & 0 & 0 & 0 & 0 \\
\hline 263 & $3 \times 10^{-6}$ & 0.2226 & 0 & 0 & 0 & 0 \\
\hline Sum & 0.58 & 4.50 & 7.48 & 8.82 & 2.27 & 1.82 \\
\hline
\end{tabular}




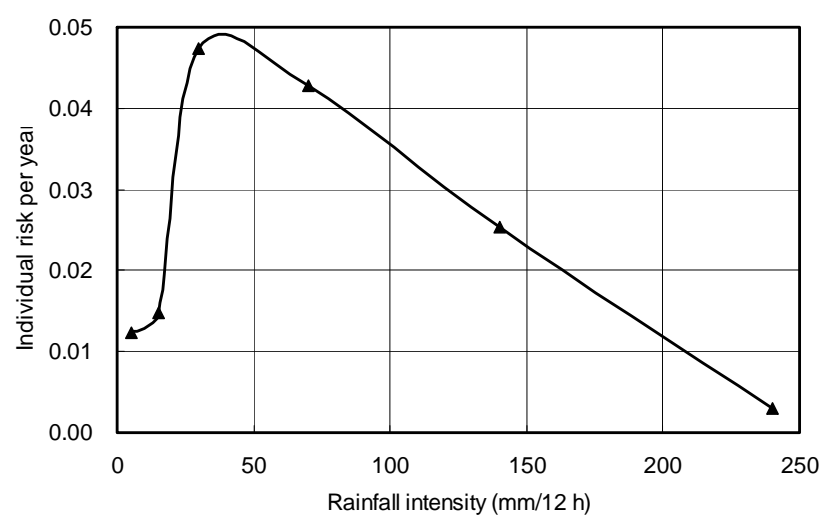

Fig. 16. Individual risk of the loose deposits between $\mathrm{K} 1$ and $\mathrm{K} 18$ shortly after the earthquake.

Especially in the cases of $30 \mathrm{~mm} / 12 \mathrm{~h}$ and $70 \mathrm{~mm} / 12 \mathrm{~h}$ rainfall scenarios, the annual individual risks reach 0.05 and 0.04 , respectively. Figures 15 and 16 represent the risk profile shortly after the earthquake. Indeed, the risk level is very high, which is not surprising, referring to the landscape shown in Figs. 5-7. Four methods to mitigate the high risks would be to: (1) change the highway alignment or use tunnels to avoid the hazardous deposits; (2) strengthen the highrisk slopes and construct rockfall barriers; (3) remove the deposits distributed in the gullies and construct debris-flow check dams and drainage channels in the gullies; and (4) implement a warning system to reduce the elements at risk in case of slope failures.

\section{Limitations}

Some assumptions and limitations in the analysis of the risks of rainfall-induced landslides should be noted: (1) the loose deposits were assumed as infinite slopes for reliability analysis; (2) the run-out distance was computed based on an empirical equation without considering local special topography conditions; (3) the soil parameters for each deposit may vary and extensive soil testing in the study area was required.

In this paper, only the risks of human life due to raininduced landslides were assessed. Assessment of economic losses and cost-benefit analyses are also of significance to the road re-construction and decision-making. The assessment of the risks of debris flows and other types of hazards should also be conducted in the future.

\section{Conclusions}

This study attempts to estimate the risks of 305 loose deposits in a quantitative manner under six rainfall scenarios. The outcomes of the slope reliability analysis combined with the findings of vulnerability and elements of risk enable the estimation of the societal and individual risks. The following conclusions can be drawn:

1. A GIS platform was used to identify hazardous loose deposits based on the Qiuckbird satellite images taken on 30 May 2008 shortly after the Wenchuan earthquake. A total of 305 loose deposits distributed along PR303 from K1 to K18 in 27 catchments have been identified. The slope gradients ranged from $6^{\circ}$ to $48^{\circ}$ and the total volume of these 305 loose deposits was approximately $4.0 \times 10^{7} \mathrm{~m}^{3}$.

2. Physically based slope stability analysis and Monte Carlo simulation were used to compute the failure probabilities of the loose soil deposits under six rainfall scenarios. The reliability analysis results were tested using observed performance of these loose deposits during the 14 August 2010 storm. A total of 112 failures were triggered by the storm, accounting for $33 \%$ of the total number of loose deposits. Seventy-nine of the 112 rainfall-induced failures were indeed evaluated as "Almost certain" to occur in the reliability analysis, with an accuracy of $71 \%$.

3. The risks posed to passengers in $\mathrm{K} 1-\mathrm{K} 18$ along PR303 have been evaluated. Both the annual societal and individual risks under the conditions of heavy rain $(30 \mathrm{~mm} / 12 \mathrm{~h})$ and torrential rain $(70 \mathrm{~mm} / 12 \mathrm{~h})$ are higher than those under the other four rain scenarios. Under the extreme rainfall condition of $240 \mathrm{~mm} / 12 \mathrm{~h}$, the failure probability is high and the consequence is very serious. However, the annual frequency is small; hence the final risk reflected in the F-N curve is not the worst. The high risk level of rainfall induced failures along PR303 reveals quantitatively the adverse impact of the Wenchuan earthquake.

Acknowledgements. The research in this paper was supported by Sichuan Provincial Transportation and Communications Department, the Research Grants Council of the Hong Kong SAR (Grant No. 622210) and State Key Laboratory of Hydroscience and Engineering (Grant No. sklhse-2012-C-01).

Edited by: O. Katz

Reviewed by: J. H. Zhang and another anonymous referee

\section{References}

Ang, A. H.-S. and Tang, W. H.: Probability concepts in engineering: emphasis on applications to civil and environmental engineering, Vol. 1, 2nd Edn., Wiley, New York, 2007.

Australian Geomechanics Society Sub-Committee on Landslide Risk Management: Landslide risk management concepts and guidelines, Aust. Geomech., 35, 49-92, 2000.

Cascini, L.: Applicability of landslide susceptibility and hazard zoning at different scales, Eng. Geol., 102, 164-177, 2008. 
Chang, D. S., Zhang, L. M., Xu, Y., and Huang, R. Q.: Field testing of erodibility of two landslide dams triggered by the 12 May Wenchuan earthquake, Landslides, 8, 321-332, 2011.

China National Standardization Commission: Short-range weather forecast, GB/T 21984-2008, Beijing, 2008 (in Chinese).

Corominas, J.: The angle of reach as a mobility index for small and large landslides, Can. Geotech. J., 33, 260-271, 1996.

Einstein, H. H.: Landslide risk-systematic approaches to assessment and management, in: Landslide risk assessment - Proceedings of the Workshop on Landslide Risk Assessment, Honolulu, Hawaii, USA, 19-21 February 1997, edited by: Cruden, D. M. and Fell, R., Balkema, Rotterdam, 25-109, 1997.

Fell, R.: Landslide risk assessment and acceptable risk, Can. Geotech. J., 31, 261-272, 1994.

Fell, R., Corominas, J., Bonnard, C., Cascini, L., Leroi, E., and Savage, W. Z.: Guidelines for landslide susceptibility, hazard and risk zoning for land use planning, Eng. Geol., 102, 85-98, 2008.

Finaly, P. J., Mostyn, G. R., and Fell, R.: Landslide risk assessment: prediction of travel distance, Can. Geotech. J., 36, 556562,1999

Fredlund, D. G. and Xing, A.: Equations for the soil-water characteristic curve, Can. Geotech. J., 31, 521-532, 1994.

Geotechnical Engineering Office (GEO): Landslides and boulder falls from natural terrain: interim risk guidelines, GEO Report No. 75, Geotechnical Engineering Office, Hong Kong, 183 pp., 1998.

Geo-Slope International Ltd.: Seep/W for finite element seepage analysis, users' manual, Geo-Slope International Ltd., Calgary, Alta, 2004.

Hunter, G. and Fell, R.: Travel distance angle for "rapid" landslides in constructed and natural soil slopes, Can. Geotech. J., 40, 1123-1141, 2003.

Legros, F.: The mobility of long-runout landslides, Eng. Geol., 63, 301-331, 2002.

Li, X., Zhang, L. M., and Fredlund, D. G.: Wetting front advancing column test for measuring unsaturated hydraulic conductivity, Can. Geotech. J., 46, 1431-1445, 2009a.

Li, X., Zhang, L. M., and Li, J. H.: Development of a modified axis-translation technique for measuring SWCCs for gravel soils at very low suctions, Geotech. Testing J., 32, 478-488, 2009b.

Morgan, G. C., Rawlings, G. E., and Sobkowicz, J. C.: Evaluating total risk to communities form large debris flows, in: Proceedings of the 1st Canadian Symposium on Geotechnique and Natural Hazards, Vancouver, Canada, 225-236, 1992.

Nadim, F., Kjekstad, O., Peduzzi, P., Herold, C., and Jaedicke, C.: Global landslide and avalanche hotspots, Landslides, 3, 159173, 2006.

Nicoletti, P. G. and Sorriso-Valvo, M.: Geomorphic controls of the shape and mobility of rock avalanches, Geol. Soc. Am. Bull., 103, 1365-1373, 1991.
Rahardio, H., Lim, T. T., Chang, M. F., and Fredlund, D. G.: Shear strength characteristics of a residual soil, Can. Geotech. J., 32, 60-77, 1995.

Reeves, A., Ho, K. K. S., and Lo, D. O. K.: Interim risk criteria for landslides and boulder falls from natural terrain, in: Proc. of the Seminar on Geotechnical Risk Management, Geotechnical Division, Hong Kong Institution of Engineers, 127-136, 1999.

Royal Society: Risk: analysis, perception and management, Report of a Royal Society Study Group, Royal Society, London, 1992.

Salvati, P., Bianchi, C., Rossi, M., and Guzzetti, F.: Societal landslide and flood risk in Italy, Nat. Hazards Earth Syst. Sci., 10, 465-483, doi:10.5194/nhess-10-465-2010, 2010.

Sassa, K., Wang, G., Fukuoka, H., Wang, F., Ochiai, T., Sugiyama, M., and Sekiguchi, T.: Landslide risk evaluation and hazard zoning for rapid and long-travel landslides in urban development areas, Landslides, 1, 221-235, 2004.

Sichuan Provincial Central Hydrological Station: Sichuan hydrology manual, Chengdu, Sichuan, 1979 (in Chinese).

Sterlacchini, S., Frigerio, S., Giacomelli, P., and Brambilla, M.: Landslide risk analysis: a multi-disciplinary methodological approach, Nat. Hazards Earth Syst. Sci., 7, 657-675, doi:10.5194/nhess-7-657-2007, 2007.

Sun, H. W.: Review of fill slope failures in Hong Kong, GEO Report 96, Geotechnical Engineering Office, Civil Engineering Department, Government of Hong Kong, Hong Kong, 1999.

Tang, W. H. and Zhang, L. M.: Development of a risk-based landslide warning system, in: Geotechnical Risk Assessment and Management, Geotechnical Special Publication No. 224, Reston, ASCE, USA, 25-49, 2011.

Wong, H. N. and Ho, K. K. S.: Travel distance of landslide debris, in: Proceedings of the 7th International Symposium on Landslides, Trondheim, Norway, edited by: Senneset, K., Balkema, Rotterdam, The Netherlands, 417-422, 1996.

Wong, H. N., Ho, K. K. S, and Chan, Y. C.: Assessment of consequence of landslides, in: Landslide risk assessment-Proceedings of the Workshop on Landslide Risk Assessment, Honolulu, Hawaii, USA, 19-21 February 1997, edited by: Cruden, D. M. and Fell, R., Balkema, Rotterdam, 111-149, 1997.

Zhang, L. L., Zhang, J., Zhang, L. M., and Tang, W. H.: Stability analysis of rainfall-induced slope failures: a review, Geotechnical Engineering, Proc. Inst. Civil Eng., 164, 299-316, 2011.

Zhang, L. L., Zhang, L. M., and Tang, W. H.: Rainfall-induced slope failure considering variability of soil properties, Geotechnique, 55, 183-188, 2005.

Zhang, L. M.: Challenges in multi-hazard risk assessment and management: Geohazard chain in Beichuan Town caused by Great Wenchuan Earthquake, in: Geotechnical Safety and Risk, Taylor \& Francis Group, London, 237-244, 2009.

Zhang, L. M., Xu, Y., Huang, R. Q., and Chang, D. S.: Particle flow and segregation in a giant landslide event triggered by the 2008 Wenchuan earthquake, Sichuan, China, Nat. Hazards Earth Syst. Sci., 11, 1153-1162, doi:10.5194/nhess-11-1153-2011, 2011. 